\title{
Online mathematics programs and the figured world of primary school mathematics in the digital era
}

\author{
Lisa Darragh ${ }^{1}$ (D) Nike Franke ${ }^{2}$
}

Received: 8 December 2020 / Revised: 30 March 2021 / Accepted: 21 April 2021

(c) Mathematics Education Research Group of Australasia, Inc. 2021

\begin{abstract}
Internet access and the availability of digital devices in classrooms have been growing exponentially. This has led to the development of subscription-based online platforms for mathematics learning, available for purchase by schools and individuals. Currently, research in mathematics education tends to focus on the benefits to teaching and learning of digital technologies, while less attention is given to the use of commercial applications in mathematics, and to the rationale of schools in choosing these resources, or to consideration of how they might fundamentally change the shape of mathematics education in our schools. This paper reports on a survey sent to mathematics leaders of all schools in Aotearoa New Zealand, attaining a 24\% response rate. Schools appeared to provide a great variety of learning experiences in mathematics, including the use of online programs. Many different online programs were utilised by schools, and the majority of these operate for business profit within state-funded school systems. The theoretical construct of 'figured worlds' was used to understand the school leaders' rationales for using the programs. Leaders gave contrasting and conflicting reasons for their choices: discourses of neoliberalism, reform teaching, traditionalism and Ed-tech were all evident in their responses. The survey results suggest that in this era of market competition, schools face pressure to provide mathematics programmes that are simultaneously traditional, modern, hightech and balanced.
\end{abstract}

Keywords Online mathematics instruction - Digital curriculum resources $\cdot$ Figured worlds · Digital technologies

Internationally and in Aotearoa New Zealand, schools have increasing access to digital devices and the internet (Attard et al., 2020; Nicholas \& Fletcher, 2017; Zheng

Lisa Darragh

1.darragh@auckland.ac.nz

1 Faculty of Education and Social Work, The University of Auckland, Auckland, New Zealand

2 Liggins Institute, The University of Auckland, Auckland, New Zealand 
et al., 2016). Correspondingly, digital technology research within mathematics education is growing, and this research has focussed particularly on teachers' use of tools and software and their benefits to students' learning (Young, 2017). Yet much less research is evident regarding a common type of tool or software, that is, online mathematics instruction programmes (OMIPs), despite their common use in schools (e.g. Day, 2013, 2014; Nicholas \& Fletcher, 2017).

OMIPS are a particular category of Digital Curriculum Resources (DCRs), which are 'organised systems of digital resources in electronic formats that articulate a scope and sequence of curricular content' (Pepin et al., 2017, p. 647). OMIPs however go beyond the e-textbook, as they are interactive and adaptive to the learner (Pepin et al., 2017). Such adaptive educational technology is also known as a 'smart learning environment', often including gamified learning (Tsatsou et al., 2019). Popular examples of OMIPs operating in Aotearoa New Zealand are Mathletics, Studyladder, Sumdog and MathsBuddy. These programs are multinational; for example, the Mathletics website flags 14 countries using the program (3P Learning, 2020), and Studyladder also operates in Australia, Canada, the USA and the U.K. (Studyladder, 2020). Many of these programs require schools or parents to purchase an annual subscription.

Like the broader digital technology field, research into OMIPs and other digital resources tends to focus on the affordances of these programs for mathematics learner cognition and motivation (Reinhold et al., 2019; Robin \& Kwak, 2018), or teacher uptake of the resources (e.g. Remillard, 2016; Utterberg et al., 2019). Further, there appears to be an assumption that the programs are inherently beneficial; there is scant literature that considers the rationale of schools for signing up to an OMIP, including how they choose from amongst the available programs. We argue it is important to understand schools' rationales, especially as the majority of programs carry a significant financial cost for either the school, the parents, or both. Borba et al. (2017) argue that digital technology is transforming the classroom; correspondingly, the use of OMIPs is also likely to alter the terrain of mathematics teaching and learning. By focussing predominantly on benefits of technologies to teaching and learning, the current research literature does not adequately, nor critically, interrogate the ways in which adoption of commercial OMIPs may change the world of mathematics learning. We suggest that gaining an understanding of schools' rationales is an important step in understanding the new world of mathematics teaching and learning in a digital era.

In this paper, we report on a survey into the uptake and rationale for the use of OMIPs in Aotearoa New Zealand primary schools. Specifically, our research questions were as follows:

- How are OMIPs used in primary schools in Aotearoa New Zealand?

- What are schools' rationales for using these programs?

- How do OMIPs alter valued practices in primary school mathematics? 


\section{Literature background}

Digital technology in mathematics education is a massive field, and research struggles to keep up with the pace of change in this area (Borba et al., 2017; Calder et al., 2018). In a review of the field over a decade, Borba et al. (2016, 2017) identified a number of trends that are relevant to the area of digital resources. These included increased use of mobile technology, availability of digital libraries such as Khan Academy and blended learning as a pedagogical approach. They concluded that: 'Mobile technology, PLNs [personal learning networks], digital learning objects and other artifacts are "stretching" the classroom, transforming the classroom to the extent that it can hardly be recognized as such' (Borba et al., 2017 , p. 230). This sentiment is echoed in a more recent survey that argues the internet is transforming or even 'deconstructing' the notion of the mathematics classroom (Engelbrecht et al., 2020, p. 826) and, furthermore, is changing the relationships between mathematical knowledge, learners and teachers. However, in these surveys, OMIPs were not an explicit focus within the changing context of mathematics education.

Research into digital apps and mobile technologies for mathematics learning (e.g. Calder et al., 2018; Larkin \& Milford, 2018) or DCR (e.g. Pepin et al., 2017) intersects with OMIPs as a field of interest. Calder et al., (2018) consider research on both commercial apps, relevant to OMIPs, but they emphasise process-type apps (such as screen-casting-see Ingram et al., 2018, geometry or coding software for example) that allow students to engage with mathematics processes. They call for rigorous theoretical frameworks to improve research about mobile technologies in mathematics education. Pepin et al. (2017) provide a conceptual review of the field of DCR in their introduction to a special issue on the topic. Their definition of DCR includes the more static e-textbook, online repositories in which teachers collaboratively build and share resources, as well as subscription-based OMIPs that are the focus of this paper. Whilst there are a number of positive aspects of DCR, including transformative learning experiences, high-quality and freely available materials, customizability of content and embedded and adaptive assessment aspects (Choppin \& Borys, 2017, p. 664), not all of these aspects apply to OMIPs. In general, articles in the special issue take a design perspective on DCR, that is, most articles are about issues of design, rather than looking at the user point of view such as examining the rationale for subscribing to expensive, ready-made OMIPs.

Some international and local research into the use of digital technology demonstrates the accelerating uptake of OMIPs. For example, Day (2013, 2014) found increasing use of Mathletics in Western Australian schools, with approximately $75 \%$ of schools using the program. Mathletics was used along with Sumdog and Studyladder in an Aotearoa New Zealand-based case study into the use of digital technology (Nicholas \& Fletcher, 2017), and Prodigy was used at one Australian school (Attard \& Holmes, 2020). In general, these studies focussed broadly on digital technology use and found OMIPs were just one feature of the digital technology landscape in schools. However, a few studies instead focussed 
on the OMIP themselves, such as Attard's (2016) examination of how Matific promotes student learning and engagement, and Muir's (2014) investigation into students' use of Khan Academy and other sites they accessed for mathematics help. Nansen et al. (2012) discussed Mathletics, which was found, in line with Day (2014), to be a popular and significant feature of children's technology use in Australia. Whilst Nansen and colleagues took a critical, ethnographic perspective, the research within mathematics education that involves OMIPs is not typically critical of these programs. One exception is Jablonka's (2017) exploration of the gamification aspects of the OMIP Sumdog, which she argued uses seduction tactics to regulate the learners' 'allegedly unpleasant mathematical activities' (pp. 550-551); in other words, the game positions regular mathematics education as 'unpleasant' in comparison to the seductively fun OMIP. Such critique provides a model for a more in-depth consideration of the role OMIPs may play in the mathematics education landscape.

Critical views of OMIPs can be found more commonly in the literature that examines the Ed-tech industry generally (Knox et al., 2020; McRae, 2013; RobertsMahoney et al., 2016; Selwyn, 2016; Wright \& Peters, 2017). These provide critiques of personalised learning and data analytics in particular, two key components of commercial OMIPs. Personalised learning is seen as being behaviourist (McRae, 2013), consumerist (Knox et al., 2020) and under-examined within education (Roberts-Mahoney et al., 2016). Similarly, the area of data analytics is not well grasped by education (Knox et al., 2020); here, concern includes the commodification of data (McRae, 2013) and the possibility that such analytics may transfer educational decision-making from the teacher to private corporations (Roberts-Mahoney et al., 2016). Ed-tech narratives are closely aligned with the narratives of neoliberalism, including the focus on the individual and the privatisation of education. In the case of OMIPs, this is a 'privatisation by stealth' as Wright and Peters (2017) argue about the Ed-tech industry in New Zealand. Such a neoliberal discourse is drawn upon in the context of mathematics education by Choppin and Borys (2017) as they note the perspectives of the private sector and policy-makers regarding DCR. Together, the narratives of Ed-tech and neoliberalism help to frame the world of mathematics learning in the digital era, a concept we develop in the next section.

\section{Theoretical framework}

To understand the data produced by this study, we use the concept of figured worlds (Holland et al., 1998). Figured worlds are part of a wider theoretical framework for understanding identity and agency in the culturally produced social context. In other words, 'figured worlds' are the context in which identities are produced (Urrieta, 2007), that is, 'a socially and culturally constructed realm of interpretation in which particular characters and actors are recognized, significance is assigned to certain acts, and particular outcomes are valued over others' (Holland et al., 1998, p. 52). Specifically, we consider 'primary school mathematics' as a figured world for the purpose of this study. Figured worlds are 
a useful concept for research in education because they illustrate the educational terrain, and in doing so highlight significant features that demonstrate a difference in or change to otherwise familiar territory.

In the figured world of primary school mathematics, the characters are students and teachers, and they are recognised in particular ways according to the culture of the world. For example, in the primary school mathematics world of 100 years ago, the students would have been recognised through the acts of listening and silently taking down notes or doing mathematics exercises. Traditionally, the teacher may have been recognised through their position at the front of the classroom and by their demonstrating at the board. In modern primary mathematics worlds, the terrain may be vastly different. We may recognise the students seated in various places of the room, working in collaboration with others to solve problems or working independently using a digital device, and we may see the teacher as a facilitator, positioned at the margins. In addition to recognising acts, a world is also produced according to the significance placed on those acts, and according to which outcomes are valued. In mathematics class, for example, we might value children attaining high test scores, or we might value instances of children working together and discussing their ideas. Of course, individual mathematics classrooms likely fall somewhere between these descriptions of modern and traditional. Nevertheless, digital platforms have the potential to alter the figured world, and we might see this in different acts recognised, or different outcomes valued, in the mathematics classroom.

Research within mathematics education has used figured worlds to understand and describe mathematics classroom practices. For example, Ma and SingerGabella (2011) note the different figured worlds of traditional mathematics, which is characterised by procedures, demonstration, and practice, and the world of reform mathematics, which is characterised by children reasoning, inventing strategies and discussing their thinking. They use these different worlds to frame their understanding in the context of teacher education (Ma \& Singer-Gabella, 2011). Various figured worlds may be applied to the same space, for example, both the figured worlds of friendship and mathematics impact differently on children's learning in the mathematics classroom (Esmonde \& Langer-Osuna, 2013; Langer-Osuna, 2015). In the secondary mathematics context, the concept of figured worlds has been applied to understanding how the course structure leads to identities of persistence in some students (Horn, 2008). These few examples demonstrate the use of the concept for understanding how the differing values, and the significance placed on various practices and types of interaction, may alter the world of mathematics learning.

In particular, we use the concept of figured worlds to examine the decisions and rationales of mathematics curriculum leaders to thus understand which acts are considered significant and which outcomes are valued. In this study, we sought specifically to understand the place of OMIPs within the figured world of primary school mathematics in the digital age. This entailed a consideration of the way OMIPs may contribute to the acts of learning and teaching mathematics as well as how OMIPs contribute to what are considered valued outcomes in mathematics education. 


\section{Methods}

An anonymous survey was sent via e-mail to every school in Aotearoa New Zealand ( 2000) that educates children at the primary level (years 1 to 8), and it was addressed to the principal or curriculum leader of mathematics (whomever felt most qualified to respond), in order to obtain just one response per school.

\section{Instrument}

The survey was online (using 'Qualtrics') and contained a mixture of closed- and open-ended questions. The closed-ended questions were dichotomous or multiplechoice and asked for school characteristics, such as type, size, location and decile rating (see Table 1). The closed questions also asked about the type of mathematics learning experiences common in the school, access to digital devices and the internet at home and at school, whether the school used OMIPs and, if so, which programs they used; which year levels used OMIPs; whether the OMIPs were used at home, at school or both; how the programs were used, and who paid for the OMIPs. The five open-ended questions asked about reasoning behind schools' choice of OMIP (both in general and regarding their specific choice), perceived benefits to students and to teachers and any hesitations or concerns regarding the use of OMIPs. The survey was developed in consultation with a group of 10 mathematics curriculum leaders

Table 1 School-level demographic characteristics $(N=477)$

\begin{tabular}{llll}
\hline Characteristic & & Number & Percent \\
\hline Type of community & Main urban & 154 & 32 \\
& Minor urban & 123 & 25.5 \\
\multirow{2}{*}{ Type of funding $(N=354)^{\mathrm{a}}$} & 199 & 41.3 \\
& Rural & 320 & 90.7 \\
& State funded & 22 & 4.6 \\
& Private & 11 & 2.3 \\
Type of school & Special character & 228 & 47.3 \\
& Full primary (year 1-8) & 166 & 34.4 \\
& Primary (year 1-6) & 37 & 7.7 \\
& Intermediate (year 7-8) & 2 & 0.4 \\
School SES & Middle school (year 7-10) & 44 & 9.1 \\
& Composite school (year 1-13) & 125 & 26.2 \\
& Low (decile 1-3) & 157 & 32.9 \\
& Mid (deciles 4-7) & 188 & 39.4 \\
\hline
\end{tabular}

${ }^{\text {a }}$ This was one of the three missing questions in the draft survey

${ }^{\mathrm{b}}$ School funding in Aotearoa New Zealand is based on the socio-economic background of schools' students, expressed in deciles. Decile 1 schools have the highest proportion of students from low socioeconomic status households and, therefore, receive the highest proportion of funding, whereas decile 10 have the lowest proportion and receive the lowest proportion of funding (www.education.govt.nz) 
from local schools. They piloted the survey and gave feedback about the wording of questions and additional questions to include. Due to a technical error, one group of respondents $(N=123)$ completed a draft version of the survey that was missing three questions. The missing questions relate mostly to financial aspects, and each is indicated in the results below. All other questions in the draft survey were identical to the final version (completed by an additional 354 respondents), and therefore, results from both $(N=477)$ are presented together.

\section{Participants}

Four hundred seventy-seven schools responded to the survey, which equals a response rate of approximately $24 \%$.

Participating schools included a large range of sizes (from 7 to 1700 students) and represented urban, semi-urban and rural communities. The majority of the respondents were leaders from schools funded by the state, either public schools or state integrated. As shown in Table 1, the proportion of schools participating in this study is not balanced by socio-economic status (SES); we would expect proportions closer to $30 \%, 40 \%, 30 \%$ for low, mid and high respectively. Here, we see a higher proportion of high decile schools, indicating a non-representative sample that is slightly skewed towards higher decile ranking.

\section{Analysis methods}

Descriptive statistics were calculated for the closed-ended questions. Pearson's correlations were calculated to explore the relationships between demographic variables. A series of $t$ tests for continuous variables and chi-square tests for categorical variables were conducted to identify any differences in school characteristics between schools that do and those that do not make use of online mathematics instructions. Quantitative analyses were conducted using statistical software SPSS (version 26).

The responses to the five open-ended questions were analysed thematically according to the methods of Braun and Clarke (2012). Firstly, the responses were read, and a code-book was developed with a list of approximately 15-20 codes for each question. In line with Braun and Clarke's methods, these codes were collapsed into around eight broader themes for each (see Tables 8, 9, 10, 11 and 12). Lisa and a research assistant independently coded all responses to allocate one or more of the themes to the response, and then met to discuss and agree upon any initial differences in coding. To give an example, one response to the first open question regarding the rationale for using OMIPs was: 'To complement the teaching that was happening at school, allow students to follow their own independent pathways and to give them a maths programme they can use at home.' This was coded in four themes: (1) to supplement the classroom programme/teaching, (2) to give support for student learning (original code: 'self-directed/agentic learning'), (3) individualised/personalised/differentiated, (4) homework/home-school link. Once we agreed on the codes and themes for each response, we tallied the totals, in order to gain 
an idea of which were the most prevalent. The themes provide an insight into what mathematics leaders saw as being the significant acts and the valued outcomes of primary mathematics education.

\section{Findings}

First, we present statistics that give an overview of the use of OMIPs and other aspects of mathematics teaching and learning in the digital era. Second, we present results of the thematic analysis, providing a qualitative description of the figured world of primary mathematics in Aotearoa New Zealand.

\section{Quantifying OMIPs in the world of primary school mathematics}

In this section, we report on the range of learning experiences offered to childrenincluding teaching via online or digital tools; the level of access to the internet and/ or digital technology; the proportion and frequency of OMIP use; which programs are used and finally information about who pays for the OMIP.

Mathematics teaching in primary schools of Aotearoa New Zealand In addition to OMIPs and other online mathematics learning, schools reported a wide variety of learning experiences offered to students. Table 2 shows the different types of learning experiences that are typical in primary schools of the digital era.

Many schools $(n=371 ; 77.8 \%)$ selected three or more options, indicating that using a variety of pedagogical methods was valued. Teaching groups based on numeracy was the most commonly reported instructional method, as indicated by other local research (e.g. Anthony \& Hunter, 2017). It is worth noting that worksheets and textbooks may also be examples of private entities profiting from education provision. The 'other' category contained a relatively large range of responses. A number mentioned the commercial programs Prlme maths, or Numicon; others used needs-based workshops or flexible grouping for children to 'opt-in'; some provided individualised programmes, games or play-based learning or inquiry-based mathematics using an integrated curriculum approach.

Table 2 Mathematics learning experiences provided in Aotearoa New Zealand primary schools $(N=477)$

\begin{tabular}{lll}
\hline Mathematics learning experiences & Number of schools & Per cent \\
\hline Teaching groups based on numeracy: & 400 & 84 \\
Mathematics via digital technologies, apps, or online learning pro- & 384 & 81 \\
grams: & & \\
Maths worksheets and/or textbooks: & 333 & 70 \\
Inquiry communities and/or collaborative problem solving: & 332 & 70 \\
Other & 63 & 13 \\
\hline
\end{tabular}


Table 3 Access to the internet at home $(N=477)$

\begin{tabular}{lll}
\hline Level of access & No. of Schools & Per cent \\
\hline All students have/are allowed access: & 79 & 17 \\
Most students have/are allowed access: & 255 & 53 \\
Many students have/are allowed access: & 88 & 18 \\
Some students have/are allowed access: & 49 & 10 \\
Almost none or no students have access: & 5 & 1 \\
\hline
\end{tabular}

Access to internet and digital devices The results suggest that many primary schools and children in Aotearoa New Zealand have a great deal of access to the internet and digital devices, as can be seen in Tables 3 and 4 . A caveat must be placed on these findings given that the survey was sent to schools via e-mail, and respondents disproportionately represent the schools in higher socio-economic areas.

Despite the high levels of access shown here, a significant equity issue is highlighted for the 54 schools in which students had only some or no access to the internet at home, and even more so in the 22 schools in which access to devices at school was very limited. For the reasons stated above, it is likely that these figures underrepresent the access issues across Aotearoa New Zealand more generally.

Schools use of OMIPs Of the 477 respondents, $377^{1}$ school leaders (79\%) indicated their school used OMIPs as part of their mathematics programme. Again, we do not claim that this figure is representative of the general proportion of primary schools in Aotearoa New Zealand, as it is probable those schools already interested in OMIPs were more likely to respond to a survey on this topic. Comparisons between schools that do and do not use OMIPs revealed no significant differences between school size, location (rural, semi-urban, and urban), decile, year levels catered for and funding source.

Table 4 Access to devices at $\operatorname{school}(N=477)$

\begin{tabular}{lll}
\hline Level of access & No. of Schools & Per cent \\
\hline A great deal (e.g. 1 to 1 devices) & 141 & 30 \\
Much (many devices in classrooms) & 257 & 54 \\
Moderate (e.g. computer lab) & 56 & 12 \\
A little & 21 & 4 \\
None at all & 1 & $<1$ \\
\hline
\end{tabular}

\footnotetext{
1 This includes 274 of the 354 who answered the full survey and 103 of the 123 who answered the draft version.
} 
The OMIPs are used frequently by students, as shown in Table 5 below:

Table 5 Frequency with which OMIPs are used-including in class and at home $(N=377)$

\begin{tabular}{lll}
\hline $\begin{array}{l}\text { How often children in the school } \\
\text { typically use OMIPs }\end{array}$ & No. of schools & Per cent \\
\hline Every day: & 61 & 16 \\
A few times a week: & 205 & 54 \\
Weekly: & 57 & 15 \\
A few times a term: & 7 & 2 \\
I have no idea: & 10 & 3 \\
No answer & 37 & 10 \\
\hline
\end{tabular}

Table 5 demonstrates that OMIPs are a significant part of the learning and teaching of mathematics in primary school-regardless of whether they comprise the entire programme or only a part of it.

Schools were found to use a large number of different OMIPs, the most common being Mathletics, Study ladder, Maths Buddy and Sumdog (see Table 6), most of which operate internationally, and most of which require subscription fees.

The cost of these programs varied. When schools sign students up for a subscription, the cost is generally lower than the cost for an individual subscription at home, for example, Mathletics costs $\$ 99$ for an individual subscription at home but is around \$20 per student via a school subscription (3P Learning, 2020). Some programmes offer free trials and others offer a free subscription as well as a paid for 'premium' version (e.g. Studyladder is free for the basic version but offers a $\$ 98$ 'premium' subscription (Studyladder, 2020) for individuals at home). Matific operates in 21 different countries and provides different instructional language options, including Te Reo Māori (Matific, 2020). E-ako (Ministry of Education, 2020) is based only in Aotearoa New Zealand (ako is a Māori term for learning), but the majority of programs are international.

Finally, Table 7 outlines who pays for the programs used by the schools.

Clearly, the majority of schools use programs that are not free; this is significant given the majority are operating within the state-funded public education system.

To summarise, we can see that OMIPs are well established in the world of mathematics teaching and learning in primary schools. To understand better the role OMIPs play in shaping this world, it is useful to examine schools' rationales for

Table 6 The OMIPs programs used by primary schools in Aotearoa New Zealand $(N=377)$

\begin{tabular}{llll}
\hline Program & Frequency & Program & Frequency \\
\hline Mathletics: & 168 & Maths Whizz: & 30 \\
Study Ladder: & 147 & Matific: & 25 \\
MathsBuddy: & 75 & Education Perfect: & 23 \\
Sumdog: & 73 & Khan Academy: & 19 \\
E-ako: & 63 & Skoolbo: & 16 \\
Prodigy: & 41 & Mangahigh: & 12 \\
IXL: & 39 & Other (<10 each) & 47 \\
\hline
\end{tabular}


Table 7 How the program/s are paid for. $(N=274)$

\begin{tabular}{lll}
\hline Who pays for the OMIP? & No. of schools & Per cent \\
\hline Parents pay: & 52 & 19 \\
The school pays: & 94 & 34 \\
Both parents and schools pay: & 57 & 21 \\
The program/s are free: & 53 & 19 \\
Missing data & 18 & 7 \\
\hline
\end{tabular}

This question appeared only on the full survey

using the programs. The next section considers the significant acts and valued outcomes as expressed through responses to the open-ended questions.

\section{Qualities of OMIPs in the figured world of primary school mathematics}

The five open-ended questions in the survey provide a detailed picture of what mathematics leaders in schools see as being the qualities of OMIPs. In this section, we give examples of responses to each question, followed by a summary of all responses, broken down into themes and with counts to indicate how common each response is. Note that many responses were coded in more than one theme.

\section{Rationale for using OMIPs}

[The] Move to 1:1 devices in Years 6,7,8 made this form of instruction easier to access. Mathletics presentation showed us the benefits of this form of individualised learning. We like Mathletics: students have to follow lessons and need to understand before moving on. Greater responsibility for self managing learning.

(State-funded full primary school, rural, decile 10)

It is not surprising to see that the main reasons given for using OMIPs were to supplement the teaching programme and support the learning of mathematics (see Table 8). Eight responses in the first category spoke about OMIPs as like having an additional teacher in the room-implying that OMIPs could stand in for the

Table 8 Themes in response to the question: Why did you choose to use an OMIP? $(N=377)$

\begin{tabular}{ll}
\hline Rationale & No. of schools \\
\hline To supplement to the classroom programme/teaching & 156 \\
Give support for student learning & 117 \\
Motivating or engaging for students & 78 \\
Homework/home-school link & 43 \\
Individualised, personalised, differentiated & 37 \\
Digital technological aspects & 30 \\
Financial aspects ('free' or 'got a deal') & 26 \\
For assessment and feedback & 21 \\
Curriculum aligned & 13 \\
\hline
\end{tabular}


Table 9 Themes in response to the question: How did you choose between the various OMIPs available?

\begin{tabular}{ll}
\hline How was the program chosen? & No. of schools \\
\hline Recommended, researched, trialled & 155 \\
Financial reasons (e.g. 'free' or offered a 'great deal') & 87 \\
For the program features & 64 \\
Relevant (e.g. to curriculum) & 57 \\
Teacher choice (e.g. each teacher chose a program for their own class) & 29 \\
Student voice (i.e. program was chosen in consultation with the students) & 26 \\
Did not choose it (e.g. 'before my time' or 'Don't know') & 26 \\
Multiple OMIPs chosen (e.g. 'for variety') & 14 \\
\hline
\end{tabular}

teacher-but the majority considered OMIPs to be just part of a 'balanced' classroom programme. This reinforces the information shown earlier in Table 2 that schools appear to be trying to provide a range of learning experiences for children. Many responses of the 'supports learning' type were generic, but some (31) specifically referenced skills practice, whereas others (23) considered OMIPs to provide 'self-directed', 'self-paced' or 'agentic' learning. These contrasting responses indicate that the nature of learning support valued in OMIPs may be quite different for different schools. Motivating students was a common theme evident in almost all the open-ended responses, and that the OMIPs provided quick and easy homework, or a method of linking home and school learning, was also evident throughout. Additionally, 13 leaders indicated that they did not choose to use the OMIPs (for example the decision was made by a previous leader).

Choice between different OMIPs

We explored all that were available and looked at cost, ease of use, information provided for teachers about student progress and achievement, ability to personalise to meet the needs of the children, and alignment with NZ curriculum. (Full primary, semi-urban school, decile 9, funding source not specified)

The majority of mathematics leaders positioned themselves as agentic consumers with only 26 responding that they had not made an active choice. The vast majority made an informed decision, for example, 71 trialled the program(/s), whilst 20 schools investigated thoroughly or conducted research: '[We] Did a study to see impact and if it lifted achievement', 32 had the program recommended by another school or professional development provider, and in 13 cases, the decision was based on direct marketing by the company 'Mathletics was the company that came to us'. A common way for companies to stand out from the others was by offering a deal or a free version of the program to trial initially. Those who referenced specific features of the program mentioned a range of aspects such as content, accessibility, resources, functionality, data, adaptive features, ease of use, additional support and customisation. It was important for schools that the program was relevant, either to the New Zealand curriculum (36) or to the specific 'needs' of the school (28), and just one school mentioned that it was available in Te Reo Māori. Finally, a few 
schools chose a variety of different OMIPs for the different levels of the school or allowed teachers to choose their own program (see Table 9).

Student benefits

Students enjoy digital use and devices. Interactive and multimedia approaches that have them engaged and wanting to complete maths tasks. Opportunity to target individualised online learning to students. Reinforce learning by providing extra opportunities to practice specific skills/tasks. Student voice told us they enjoy using [them]. Students that are motivated extrinsically can achieve points and certificates. Can easily be used in class programme during tumbles/ rotations.

(State-funded intermediate school, semi-urban, decile 8)

Table 10 highlights that many schools saw a significant benefit to children in that the OMIPs were enjoyable, engaging, fun or motivating. Often, it was the visual, interactive nature of the programs or the rewards of embedded games that were considered engaging. Relatedly, some responses implied it was the digital aspects that were inherently beneficial such as the online platform, the 'different mode of learning' or the adaptive/responsive nature of the programs and the 'rewindable' instruction. The 'instant feedback' of the OMIPs was another often-cited digital benefit. A large number of responses noted the benefit of practicing skills taught previously, but in contrast to these 108 responses, there were nine responses indicating that the OMIPs were useful for new learning, for example via video instruction, and 30 considered OMIPs to be an 'additional teacher. Another large category of response related to the ability of OMIPs to 'personalise' for the individual learner-highlighting a key value in mathematics learning. We noted nine responses that were cautious or denied the benefit of the programs, for example: 'I have not seen any benefits as I have not been using them in class' and 'I have reservations about their use and am considering researching more into this'. Finally, there were also 50 responses that could only be interpreted as being of benefit to teachers, rather than students, which we attributed to misreading of the survey questions. Similarly, 23 responses to the following question about teacher benefits could only be understood as being a benefit to students.

Table 10 Themed responses to the question: What do you see are the benefits to students?

\begin{tabular}{ll}
\hline Benefit to students & No. of schools \\
\hline Enjoyable/fun/motivating & 157 \\
Practice or consolidate other learning in class & 108 \\
Individualised/differentiated/personalised & 103 \\
Digital benefits & 94 \\
Promote student agency/independence & 56 \\
Feedback on learning (e.g. 'instant feedback') & 55 \\
Home-school link & 44 \\
Provides an additional teacher & 30 \\
Aligned to curriculum & 10 \\
Easy to use & 6 \\
\hline
\end{tabular}


Table 11 Themed responses to the question: What do you see are the benefits to teachers of OMIPs?

\begin{tabular}{ll}
\hline Benefit to teachers & No. of schools \\
\hline Support to overall programme & 124 \\
Assessment and feedback & 123 \\
Supports children's learning (e.g. individualisation, & 110 \\
$\quad$ motivation) & 82 \\
Support for teaching & 23 \\
Digital aspect, (e.g. flipped learning, trendy, video & \\
$\quad$ instruction) & 22 \\
Home-link & 13 \\
Curriculum aligned & 8 \\
Teacher learning/need &
\end{tabular}

Teacher benefits

[It] doesn't replace the teacher in our school. It is additional to. Reduces photocopying. Provides an instant picture of the progression of learning. Teachers can set ... tasks that are additional but follow up on the targeted teaching they are doing. A student's curriculum can be personalised so their home page is reflective of what is easy, instructional and just stretching them a bit further - so they know where they are heading. Each child can have a defined individual programme. Parents have immediate access. Shared ownership. Students enjoy it and see the benefits. It doesn't replace what only the teacher can do which is be responsive to the emerging needs. Slow down, speed up, intervene.

(State-funded intermediate school, semi-urban, no decile specified)

Many of the responses coded 'support to overall programme' (see Table 11) mentioned that the OMIP was part of a 'maths rotation activity'. This reflects the large number of primary schools in Aotearoa New Zealand that still arrange mathematics classes into smaller groups (typically 'ability groups', see also Anthony \& Hunter, 2017) and rotate the groups around a number of activities (see also Table 2 showing 400 schools teaching numeracy groups). The embedded assessment and tracking functions of the programs are also highly valued by schools, perhaps in part as a time-saving device. Indeed, many of the comments related to 'support for teaching' referenced the time teachers could save not having to find other resources or activities for the children's learning. Eight responses referred to teacher learning, for example by providing a model of an alternative instructional approach; here, the implication was that teachers sometimes require pedagogical content knowledge that might be provided by the OMIPs. Just three responses said that it was not actually beneficial for teachers.

\section{Hesitations and concerns}

We have a contract with Mathletics which we will not be renewing - lots of support initially then not interested - just about money? Also they cannot replace great teaching to shift student achievement - only support it.

(State-funded full primary school, rural, decile 7) 
As can be seen in Table 12, a large proportion had no hesitations or concerns at all. Stated concerns could be categorised as either related to teachers or students. Comments regarding teachers included the worry that teachers would become over-dependent on the OMIPs, or that it would require more work such as extra monitoring/supervision or individualising the programs to make them relevant. Concern for children included negative aspects of the technology such as 'gamification', 'kids playing with avatars', too much screen-time and addiction issues. Other concerns were for the children's learning - the OMIPs were seen to lack problem solving, critical thinking, context and the benefit of using physical manipulatives. Relatedly, there was the concern that the OMIPs could be boring, irrelevant 'busy work' or lead to children being off-task. Just 14 mentioned concern with the cost of the programs.

Summary Taking the qualitative responses together, we can see that most of the themes were evident in many or all of the qualitative responses. In short, OMIPs were seen as being supportive to the overall mathematics programme rather than a replacement. This was evident in the comments related to variety and balance. OMIPs were seen as a way of making the boring practice aspect of maths fun. The programs provide assessment data in the form of feedback to students and, more usefully, data for teachers. They were seen to be an easy way to link with the home. The programs were valued because they provide individualised learning that is aligned to the curriculum and primarily reinforce basic facts or maintain previous learning. Finally, value was seen in having student- and teacher-agency in the choice of programs and learning pathways within those programs, and there is an inherent benefit seen in the digital aspects of the programs. These findings highlight the sorts of acts that are recognised and the outcomes that are valued in the digital era of teaching and learning mathematics at primary school, as will be discussed further in the following section.

Table 12 Themed responses to the question: Do you have any hesitations or concerns about the use of OMIPs?

\begin{tabular}{ll}
\hline Hesitations or concerns (note $N=274)$ & No. of schools \\
\hline None & 88 \\
Teacher dependence/over use & 37 \\
Digital aspects negative for students & 36 \\
More work for the teacher & 32 \\
Lacks quality mathematics & 28 \\
Irrelevant/ boring & 19 \\
Off task children & 18 \\
Financial aspects & 14 \\
Curriculum and content & 11 \\
Logistical issues (e.g. young children logging on, & 4 \\
reading ability) & \\
\hline
\end{tabular}




\section{Discussion: mapping the figured world of primary mathematics in the digital era}

It is clear from the survey responses that the figured world of primary mathematics has evolved from the traditional and teacher-centred world. Here, we may recognise a variety of acts in this world, such as using digital technologies, practicing skills, agentic learning/teaching and data-driven assessment practices. The valued outcomes in this world include variety and balance, motivated and engaged students, individualised learning and home-school links. It is worth considering how these acts and outcomes match with those of 'reform' and 'traditional' mathematics classrooms (e.g. Ma \& Singer-Gabella, 2011).

The reform mathematics classroom is student-centred, and this is a value that was strongly evident in the survey data. Arguably, the notion of an individualised program is the ultimate in student-centred learning-although a counter argument is that OMIPs are instead device-centred. Student agency was highly valued by schools, and this was exemplified by schools that chose to use OMIPs in consultation with students—often termed 'student voice'-when explaining their choice. The idea of student agency is also embedded in programs that enable learners to pick their own pathway through the learning experiences offered. However, this may be a false agency as the programs are designed to constrain that choice in ways that are not apparent to the user (Knox et al., 2020). Whilst the student-centred and agentic aspects of the reform-mathematics narrative were drawn on by school leaders in their rationale, other aspects, such as collaborative problem solving, are not catered for by OMIPs, as some leaders acknowledged when they spoke about the need for a 'balanced programme'.

The other end of the reform-traditional dichotomy was also clearly evident in school leader responses. The need to 'practice skills' (albeit in a fun way) was an often-cited rationale. This traditional narrative (Ma \& Singer-Gabella, 2011) enjoys a more natural pairing with the OMIPs, particularly those that rely heavily on game-based drilling of basic facts. This response evokes Jablonka's (2017) critique of OMIP Sumdog and the assumption that fun games are required for children to engage in the essential, but boring, practicing of mathematics skills. It should be noted that some school leaders expressed concerns here, worried about screen time and addiction or the boring and repetitive nature of some programs.

Yet, neither the reform nor traditional narratives capture the variety of valued acts and outcomes expressed by school leaders. In addition to reform and traditional, there was also clear evidence of the often-paired narratives of 'Ed-tech' and 'neoliberal' ideology, particularly in the aspects of individualised learning and data analytics.

Whilst at first glance individualised, personalised or differentiated learning may appear to draw on a student-centred view of learning, it is a narrative that has been harnessed by the Ed-tech industry and is rooted in neoliberalism. Neoliberal ideology relies on ideas of individual competition in the marketplace (Wright \& Peters, 2017; Youdell, 2011). Here, education is seen as a means by which the individual child may 'get ahead of the pack' and be rewarded lucratively when they complete their education. There is little place for collaborative problem-solving in this context (nor for communication, creativity or critical 
thinking). Furthermore, the personalisation of OMIPs conceptualises learning as the acquiring of skills through behaviour modification (Roberts-Mahoney et al., 2016), perhaps not quite the vision of school mathematics.

Individualised learning at a large scale is made possible by data analytics. The ability to provide instant feedback and the advantage of automatic assessment systems were certainly seen as beneficial by school leaders; this was one of the largest perceived teacher benefits of OMIPs. However, Knox et al. (2020) argue that education has been slow to grasp the implications of 'big data' and learning analytics that are inherent to the assessment systems in OMIPs. Not only is the data owned by the corporation, but learning decisions are transferred from the teacher to the private sector (Roberts-Mahoney et al., 2016) because it is the OMIP analytics that decide the next steps for students' learning. The need for comprehensive assessment data also demonstrates the high degree of accountability placed on teachers who face the need to prove their students are learning and making progress. The OMIPs have cleverly capitalised on this pressure facing schools and teachers in current times.

Finally, there is a narrative around the perceived inherent benefits of digital technology permeating the data. In every open-ended response, the category of digital technology features, particularly in reasons given for the particular choice of OMIP ('features of the program') and the perceived benefits to students. We might call this the Ed-tech narrative, as it is the one produced and reproduced by the Ed-tech industry. Selwyn (2016) elaborates on Ed-tech discourse, as follows:

Ed-tech Speak is highly political in both its nature and its effect. These should not be treated simply as benign or neutral words, terms, phrases and statements. Instead, these are powerful means of advancing the interests and agendas of some social groups over the interests of others. (p. 438)

Whilst occasionally leaders' rationales drew on the specific advantages of the technology, such as rewindable instruction, adaptive programs or interactivity, oftentimes the rationale seemed to imply that OMIPs were a good thing simply because they were digital and appealing to students already immersed in a digital world. Some school leaders suggested either explicitly or implicitly that since they had devices in the classroom, they needed to put them to use in some way. However, beyond a few comments about financial issues, the school leaders' hesitations did not consider any agenda on the part of the private entity who owned the OMIP.

\section{Limitations and areas for future research}

As previously noted, the high-skewed SES of the school communities who responded to the survey means that lower SES schools are less represented in this data. This must be considered when interpreting results, particularly those that relate to financial aspects. It is likely the voices of schools that simply cannot afford OMIPs, nor afford to pass on the cost to their communities, have not been heard. Secondly, the survey has not captured the voice of classroom teachers to understand 
their experience of working with OMIPs during mathematics lessons, nor that of the students. These are areas for future research — as would be an extension to the research into the secondary school context. Another future area of research might be an objective examination of the extent to which OMIPs do (or do not) improve learning - of mathematical concepts as well as mathematical processes such as communication, problem solving and logical thinking.

\section{Implications and conclusions}

Calder et al. (2018) called for rigorous theoretical frameworks in mathematics education and technology research. Here, we may see that figured worlds (Holland et al., 1998) provide a useful theoretical lens to understand some modern mathematics education practices with a particular type of digital technology. However, typically, the concept of figured worlds is applied with a much closer zoom lens-such as an in-depth examination at the classroom level (see for example, Esmonde \& Langer-Osuna, 2013; Langer-Osuna, 2015; Radovic et al., 2017). It would certainly be useful to apply this closer look at a single classroom or school to investigate, for example, the use of OMIPs in innovative learning environments (ILEs) and/or single-cell classrooms that utilise an inquiry approach. This may afford an understanding of student or teacher identity and agency in conjunction with OMIP use. Such an in-depth look may also consider access to quality learning of mathematics and the extent to which the world of primary mathematics learning is fundamentally different—or perhaps in some ways unchanged. This study, however, has given a broad view of OMIP use affecting the modern mathematics education landscape.

It is clear from the survey data that OMIPs have been absorbed into the world of teaching and learning mathematics in primary schools of Aotearoa New Zealand. But it is equally clear that the OMIPs have not replaced other mathematics pedagogy; rather, we see an additive effect. In other words, the figured world is becoming increasingly complex. The huge variety of rationales behind the choice to use OMIPs also demonstrates the complexities involved in making decisions about teaching and learning mathematics, considering the variety of significant acts and valued outcomes. It seems teachers are required to cater to both reform and traditional mathematics, as well as utilise digital platforms, and then on top of this to maintain a 'balanced programme'.

We argue that four key narratives influence schools' decision-making about mathematics: reform, traditional, Ed-tech, neoliberalism. These narratives do not all cohere well together, but it seems schools are trying to provide for each of them. Youdell (2011) argues that schooling is shaped and constrained by the prevailing politics of the moment...' (p. 7). However, in this data, we can see that it is also shaped by the politics of the past; it appears schools are not replacing old with new; they try to do it all. We should also consider the competitive 'school choice' context in which these schools operate; the survey results suggest that schools may face pressure to provide educational that caters for their students in every possible way. This could make them vulnerable to programs that promise to provide exactly this 
comprehensive coverage despite, in many cases, involving a financial cost to the school, parents, or both.

At the time of writing, the world is still grappling with the COVID-19 pandemic, including school closures and having to provide distance learning for students at all levels. Possibly, this context heralds massive change in education, and we might see OMIPs and other private providers of online instruction cementing themselves further in the figured world of primary school mathematics. Indeed, Ed-tech companies have already ramped up their marketing in response to pandemic conditions (Williamson et al., 2020). Although the major theme we saw in the data was that schools tempered their rationales for using OMIPs with the notion of them being just part of a balanced programme, a key question for mathematics education remains: How might schools manage to juggle this balance in years to come?

Acknowledgements We would like to thank our research assistant Rachel Woods for all her hard work recruiting participants and engaging in the coding process.

Funding The study was funded by an internal grant from The University of Auckland: FRDF no. 3716971 .

Data availability A copy of the survey used is available on request.

\section{Declarations}

Ethics approval Ethics approval was granted by University of Auckland Human Participants Ethics Committee on 7th September 2018 Ref. 021923.

Conflict of interest The authors declare no competing interests.

\section{References}

3P Learning. (2020). Mathletics. https://www.mathletics.com/nz/

Anthony, G., \& Hunter, R. (2017). Grouping practices in New Zealand mathematics classrooms: where are we at and where should we be? New Zealand Journal of Educational Studies, 52, 73-92.

Attard, C. (2016). Research evaluation of Matific mathematics learning resources: project report. Retrieved from https://doi.org/10.4225/35/57f2f391015a4

Attard, C., Calder, N., Holmes, K., Larkin, K., \& Trenholm, S. (2020). Teaching and learning mathematics with digital technologies. In Research in mathematics education in Australasia 2016-2019 (pp. 319-347). Springer.

Attard, C., \& Holmes, K. (2020). "It gives you that sense of hope": an exploration of technology use to mediate student engagement with mathematics. Heliyon, 6(1). https://doi.org/10.1016/j.heliyon. 2019.e02945

Borba, M., Askar, P., Engelbrecht, J., Gadanidis, G., Llinares, S., \& Aguilar, M. S. (2016). Blended learning, e-learning and mobile learning in mathematics education. ZDM, 48, 589-610. https://doi.org/ 10.1007/s11858-016-0798-4

Borba, M., Askar, P., Engelbrecht, J., Gadanidis, G., Llinares, S., \& Aguilar, M. S. (2017). Digital technology in mathematics education: research over the last decade. In G. Kaiser (Ed.), Proceedings of the 13th International Congress on Mathematical Education ICME-13 (pp. 221-233). Hamburg, Germany: Springer Open.

Braun, V., \& Clarke, V. (2012). Thematic analysis. In H. Cooper, P. Camic, L. D., A. Panter, D. Rindskopf, K. Sher, \& J. Kenneth (Eds.), APA Handbook of research methods in psychology: vol. 
2. Research designs: quantitative, qualitative, neuropsychological, and biological (pp. 57-71). Washington, D.C.: American Psychological Association. https://doi.org/10.1037/13620-004

Calder, N., Larkin, K., \& Sinclair. (2018). Mobile technologies: how might using mobile technologies reshape the learning and teaching of mathematics? In Using mobile technologies in the teaching and learning of mathematics (pp. 1-6). Springer.

Choppin, J., \& Borys, Z. (2017). Trends in the design, development, and use of digital curriculum materials. $Z D M, 49(5), 663-674$.

Day, L. (2013). A snapshot of the use of ICT in primary mathematics classrooms in Western Australia. APMC, 18(1), 16-24.

Day, L. (2014). ICT the changing landscape. Australian Primary Mathematics Classroom, 19(2), $23-27$.

Engelbrecht, J., Borba, M., Llinares, S., \& Kaiser, G. (2020). Will 2020 be remembered as the year in which education was changed? ZDM - Mathematics Education, 52, 821-824.

Esmonde, I., \& Langer-Osuna, J. M. (2013). Power in numbers: student participation in mathematical discussions in heterogeneous spaces. Journal for Research in Mathematics Education, 44(1), 288-315. https://doi.org/10.5951/jresematheduc.44.1.0288

Holland, D., Skinner, D., Lachicotte, W., \& Cain, C. (1998). Identity and agency in cultural worlds. Harvard University Press.

Horn, I. S. (2008). Turnaround students in high school mathematics: constructing identities of competence through mathematical worlds. Mathematical Thinking and Learning, 10(3), 201.

Ingram, N., Pratt, K., \& Williamson-Leadley, S. (2018). Using show and tell apps to engage students in problem solving in the mathematics classroom. In N. Calder, K. Larkin, \& N. Sinclair (Eds.), Using mobile technologies in the learning of mathematics. Heidelberg, Germany.

Jablonka, E. (2017). Gamification, standards and surveillance in mathematics education: an illustrative example. In A. Chronaki (Ed.), Mathematics education and life at times of crisis: Proceedings of the ninth international mathematics education and society conference. Mathematics education and society.

Knox, J., Williamson, B., \& Bayne, S. (2020). Machine behaviourism: future visions of "learnification" and "datafication" across humans and digital technologies. Learning, Media and Technology, 45(1), $31-45$.

Langer-Osuna, J. (2015). Linear equations and rap battles: how students in a wired classroom utilized the computer as a resource to coordinate personal and mathematical positional identities in hybrid spaces. Mathematics Education Research Journal, 27(1), 51-64. https://doi.org/10.1007/ s13394-014-0125-8

Larkin, K., \& Milford, T. (2018). Mathematics apps - stormy with the weather clearing: Using cluster analysis to enhance app use in mathematics classrooms. In Using mobile technologies in the teaching and learning of mathematics (pp. 11-30). Springer.

Ma, J. Y., \& Singer-Gabella, M. (2011). Learning to teach in the figured world of reform mathematics: negotiating new models of identity. Journal of Teacher Education, 62(1), 8-22. https://doi.org/10. 1177/0022487110378851

Matific. (2020). Matific. https://www.matific.com/nz/en-nz/home/

Ministry of Education. (2020). E-Ako. https://e-ako.nzmaths.co.nz/

McRae, P. (2013). Rebirth of the teaching machine through the seduction of data analytics: this time it's personal [Online resource]. Retrieved from https://nepc.colorado.edu/blog/rebirth-teaching-machinethrough-seduction-data-analytics-time-its-personal

Muir, T. (2014). Google, Mathletics and Khan Academy: students' self-initiated use of online mathematical resources. Mathematics Education Research Journal, 26, 833-852. https://doi.org/10.1007/ s13394-014-0128-5

Nansen, B., Chakraborty, K., Gibbs, L., Vetere, F., \& MacDougall, C. (2012). "You do the math": Mathletics and the play of online learning. New Media \& Society, 14(7), 1216-1235. https://doi.org/10. $1177 / 1461444812442926$

Nicholas, K., \& Fletcher, J. (2017). What is happening in the use of ICT mathematics to support young adolescent learners? A New Zealand experience. Educational Review, 69(4), 474-489. https://doi. org/10.1080/00131911.2016.1237476

Pepin, B., Choppin, J., Ruthven, K., \& Sinclair, N. (2017). Digital curriculum resources in mathematics education: foundations for change. ZDM - Mathematics Education, 49, 645-661.

Radovic, D., Black, L., Salas, C. E., \& Williams, J. (2017). Being a girl mathematician: diversity of positive mathematical identities in a secondary classroom. Journal for Research in Mathematics Education, 48(4), 434-464. Retrieved from https://www.jstor.org/stable/10.5951/jresematheduc.48.4.0434 
Reinhold, F., Hoch, S., \& Reiss, K. (2019). Research potential of interactive textbook perspectives for research in mathematics education. In S. Rezat, L. Fan, M. Hattermann, J. Schumacher, \& H. Wuschke (Eds.), Proceedings of the Third International Conference on Mathematics Textbook Research and Development (pp. 37-38). Paderborn: Universitatsbibliothek Paderborn.

Remillard, J. (2016). Keeping an eye on the teacher in the digital curriculum race. In M. Bates \& Z. Usiskin (Eds.), Digital curricula in school mathematics. (pp. 195-204). Information Age Publishing.

Roberts-Mahoney, H., Means, A. J., \& Garrison, M. J. (2016). Netflixing human capital development: personalized learning technology and the corporatization of K-12 education. Journal of Educational Policy, 31(4), 405-420. https://doi.org/10.1080/02680939.2015.1132774

Robin, K., \& Kwak, J. Y. (2018). Comparing types of mathematics apps used in primary school classrooms: an exploratory analysis. Journal of Computers in Education, 5(3), 349-371. https://doi.org/ $10.1007 / \mathrm{s} 40692-018-0109-\mathrm{x}$

Selwyn, N. (2016). Minding our language: why education and technology is full of bullshit ... and what might be done about it. Learning, Media and Technology, 41(3), 437-443. https://doi.org/10.1080/ 17439884.2015 .1012523

Studyladder. (2020). Studyladder. https://www.Studyladder.co.nz

Tsatsou, D., Vretos, N., \& Daras, P. (2019). Adaptive game-based learning in multi-agent educational settings. Journal of Computers in Education, 6(2), 215-239.

Urrieta, L. J. (2007). Figured worlds and education: An introduction to the special issue. The Urban Review, 39(2), 107-116. https://doi.org/10.1007/s11256-007-0051-0

Utterberg, M., Tallvid, M., Lundin, J., \& Lindström, B. (2019). Challenges in mathematics teachers' introduction to a digital textbook: analyzing contradictions. Journal of Computers in Mathematics and Science Teaching, 38(4), 337-359.

Williamson, B., Eynon, R., \& Potter, J. (2020). Pandemic politics, pedagogies and practices: digital technologies and distance education during the coronavirus emergency. Learning, Media and Technology, 45(2), 107-114. https://doi.org/10.1080/17439884.2020.1761641

Wright, N., \& Peters, M. (2017). Sell, sell, sell or learn, learn, learn? The Ed-tech market in New Zealand's education system - privatisation by stealth? Open Review of Educational Research, 4(1), 164176. https://doi.org/10.1080/23265507.2017.1365623

Youdell, D. (2011). School trouble. Routledge.

Young, J. (2017). Technology-enhanced mathematics instruction: a second-order meta-analysis of 30 years of research. Educational Research Review, 22, 19-33.

Zheng, B., Warschauer, M., Lin, C.-H., \& Chang, C. (2016). Learning in one-to-one laptop environments: a meta-analysis and research synthesis. Review of Educational Research, 86(4), 1052-1084.

Publisher's Note Springer Nature remains neutral with regard to jurisdictional claims in published maps and institutional affiliations. 